\title{
Self-publishing editor set to retire
}

The editor of a theoretical-physics journal, who was facing growing criticism that he used its pages to publish numerous papers written by himself, is set to retire early next year.

Five of the 36 papers in the December issue of Chaos, Solitons and Fractals alone were written by its editor-in-chief, Mohamed El Naschie. And the year to date has seen nearly 60 papers written by him appear in the journal.

A civil engineer by training, El Naschie attempts to combine aspects of particle physics and chaos theory. Many of his papers revolve around the idea that fractal properties of spacetime can influence elemental particles and physical constants.

Most scientists contacted by Nature comment that El Naschie's papers tend to be of poor quality. Peter Woit, a mathematical physicist at Columbia University in New York, says he thinks that "it's plain obvious that there was either zero, or at best very poor, peer review, of his own papers". There is, however, little evidence that they have harmed the field as a whole.

El Naschie, who was born in Cairo and now splits his time between England and Germany, rejects any charges of sloppy peer review. "Our papers are reviewed in the normal way expected from a scientific international journal published by a reputable international publisher," he told Nature in an e-mail signed by P. Cooper, who claimed to be a spokesperson for the editorial board of Chaos, Solitons and Fractals. Elsevier, which publishes the journal, is a member of the Committee on Publication Ethics, which holds that good editors "ensure that all published reports of research have been reviewed by suitably qualified reviewers".

On 25 November, Elsevier's director of corporate relations, Shira Tabachnikoff, wrote an e-mail to Nature saying: "Dr El Naschie's retirement as Editor-in-Chief of Chaos, Solitons and Fractals will be announced to readers in the first issue of 2009. Elsevier and Dr El Naschie have been in discussion for quite some time about the details of his retirement and the transitional arrangement for papers under review."

In a separate e-mail Tabachnikoff wrote: "[We are] committed to supporting our editors in maintaining high standards for both the editorial and peer-review process. At times there may be discussions about particular scientific issues and fields, even at the level of individual editorial decisions. That is a part of the normal process of scientific publishing."

El Naschie defended the journal's publication record, saying: "We put more emphasis on the scientific content and the originality of

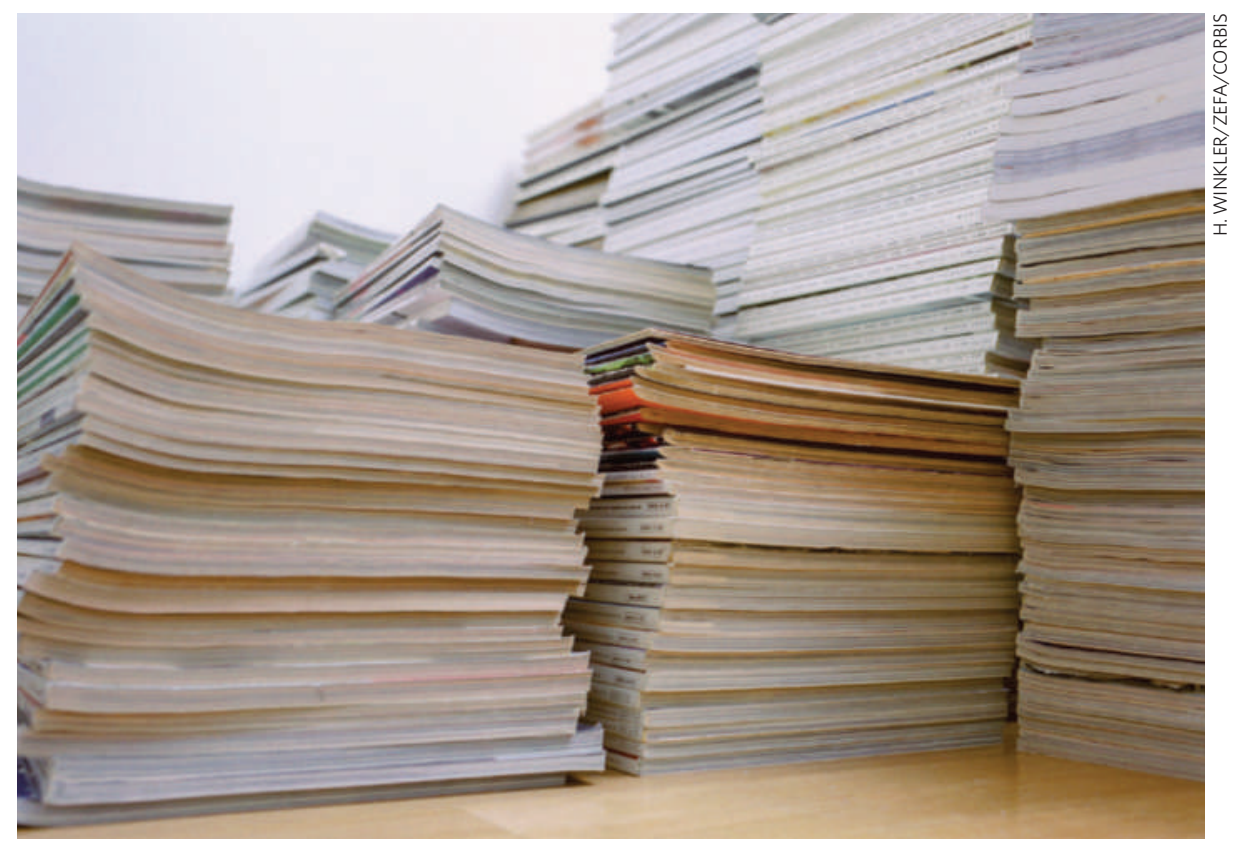

Apparent misuse of editorial privileges has sparked calls for a clearer peer-review process across journals.

the papers and slightly less emphasis on prestigious addresses and impressive affiliations." His website lists a number of such affiliations, including honorary professorships at Shanghai Jiao Tong University and Donghua University, also in Shanghai. By his own account, which could not be confirmed by Nature despite a number of attempts, he is an adviser to the Egyptian Ministry for Science and Technology and a principal adviser to the Ministry of Science and Technology of Saudi Arabia.

But he is not, as he claims on his website, a distinguished fellow of the Institute of Physics at the Johann Wolfgang Goethe University in Frankfurt, Germany, says Walter Greiner, a former director of the institute. Greiner also says El Naschie has ignored his requests to remove his name from the list of members of the journal's honorary editorial board. Through Cooper, El Naschie says that it would not be "appropriate" to address these concerns.

Chaos, Solitons and Fractals was founded by El Naschie in 1991. It costs US $\$ 4,520$ a year, and usually comes bundled with access to other Elsevier journals. Most large research organizations have electronic access for this reason.

The journal has a relatively high impact factor of 3.025 for 2007. But that may be the result of a high rate of self-citation, says Zoran Škoda, a theoretical physicist at the Ruđer Bošković Institute in Zagreb, Croatia. Of the 31 papers not written by El Naschie in the most recent issue of Chaos, Solitons and Fractals, at least 11 are related to his theories and include 58 citations of his work in the journal.

In May, Škoda sent letters to members of the journal's editorial board asking whether they agreed with El Naschie's editorial practices. In return, he says, he and his institute director received a letter, signed by a P. Green who identified himself or herself as a legal adviser to the editorial board, threatening legal action should Škoda continue sending "defamatory" letters.

Škoda notes that Ji-Huan He, the journal's regional editor for China and a mechanical engineer and computer scientist at Donghua University, also cites El Naschie's work frequently. The current issue of the journal has one paper by He that cites himself 14 times and El Naschie twice. He is also editor of the International Journal of Nonlinear Sciences and Numerical Simulation, which in a 2005 editorial said: "Men of genius like Einstein and Elnaschie very often ask some straightforward and seemingly innocent questions, which may turn out to have undreamed of answers."

A small minority of physicists cautiously recognizes the originality of El Naschie's ideas. "They're at least interesting," says Werner Martiennsen, a retired physicist at the Johann Wolfgang Goethe University, and one of the regional editors for Europe on Chaos, Solitons and Fractals.

Quirin Schiermeier 